\title{
Histopathological characteristics of dental socket healing on collagen density following use of pangas catfish (Pangasius djambal) gelatin
}

\author{
Fredy Mardiyantoro*® ${ }^{\star}$ Nenny Prasetyaningrum**, Hani Tri Rahmastuti* \\ *Department of Oral \& Maxillofacial Surgery, Faculty of Dentistry, University of Brawijaya, East Java, Indonesia \\ **Department of Oral Biology, Faculty of Dentistry, University of Brawijaya, East Java, Indonesia \\ *JI Veteran Malang, East Java, Indonesia; $₫$ correspondence: fredymardiyantoro@gmail.com
}

Submitted: $19^{\text {th }}$ October 2018; Revised: 11 ${ }^{\text {st }}$ February 2019; Accepted: $2^{\text {th }}$ February 2019

\begin{abstract}
Tooth extraction is a common treatment in dental practice. However, complications such as bleeding or dry socket may occur during healing process. Pangas catfish (Pangasius djambal) gelatin contains glutamine which could increase the proliferation of fibroblast, accordingly collagen synthesis increases. The study aimed to demonstrate collagen density after the application of pangas catfish gelatin on post-tooth extraction wound of albino rats (Rattus norvegicus). This was an experimental study with randomized posttest-only control group design which involved male Wistar strain albino rats. The rats were selected using a random sampling method and divided into four groups, namely day-3 control group ( $n=7$ ), day-7 control group $(n=7)$, day-3 treatment group $(n=7)$ and day-7 treatment group $(n=7)$. Pangas catfish gelatin was administered into the socket once after extraction. The variable measured in the study was collagen density, determined by collagen scoring of hematoxylin eosin-stained histopathological preparations. Collagen formation were determined according to the assessment criteria of collagen distribution and density. Data analysis showed there was a significant difference of collagen synthesis between the control and treatment groups according to Kruskal-Wallis test of which the result of control group day-3 was $1.13 \pm 0.34$, control group day-7 was $1.76 \pm 0.67$, treatment group day-3 was $1.66 \pm$ 0.47 and treatment group day-7 was $2.93 \pm 0.25$. In addition, the day-7 treatment group showed the highest collagen scoring values as compared to the control groups according to the Mann-Whitney test $(p<0.05)$. In conclusion, pangas catfish gelatin increased collagen density during dental socket healing process after tooth extraction in albino rats.
\end{abstract}

Keywords: collagen; Pangasius djambal; pangas catfish gelatin; tooth extraction

\section{INTRODUCTION}

Tooth extraction is one of the dental procedures in dentistry that leaves surgical wound and has complications such as excessive bleeding and dry socket. Wound healing is a process of replacement and repair of damaged tissue functions. Characteristics of healing for all types of wound are similar, but may vary depending on the site, severity, and extent of injury. The process of wound healing involves four major phases, including hemostasis, inflammatory, proliferative, and remodeling phase. In tooth extraction, this process involves soft tissues and bone remodeling in the alveolar socket. ${ }^{1,2}$ In this study, the postextraction proliferation process was evaluated in terms of collagen density. Histological analysis shows that wound healing processes involve overlapping phases, followed by the presence of migration and proliferation of mesenchymal stem cells, inflammatory cells infiltration, angiogenesis, fibroblast proliferation, collagen synthesis, as well as bone formation and remodeling. ${ }^{3}$

Collagen has a crucial role in wound healing process. The role of collagen including increasing exudate, cellular components, growth factor, as well as interaction with fibronectin, promoting fibroplasia process, and assisting homeostasis process. Collagen is also highly required for repairing damages and restoring tissues' anatomical structure and function. ${ }^{4,5}$ Mucosal wound healing occurs in 5 to 7 days. From day- 3 onwards, the increase in collagen synthesis occurs and continues up to the second week. ${ }^{6}$ In this study collagen synthesis was expected to increase, thus accelerate wound healing process. 
Studies showed the use of gelatin affects wound healing processes. Gelatin is a type of protein extracted from collagen tissue of skin, bone, or animals' connective tissues. Raw materials used for gelatin extraction are commonly from bovine or porcine. However, utilization of gelatin from animals has potential risk of spreading hand, foot, and mouth disease (HMFD). ${ }^{7,8}$ Accordingly, alternative source of gelatin regarding such health-related concern is fish. In terms of fish as a source of raw material for gelatin extraction, warm-water fish gelatin has more similar characteristics to bovine gelatin as compared to cold-water fish gelatin..$^{9,10,11}$

One of the aquaculture commodities which may be utilized as gelatin source is pangas catfish (Pangasius djambal). Pangas catfish is a freshwater fish from Indonesia. It is commonly consumed and distributed in some parts of Sumatra, Java, and Kalimantan. Ratnasari et al. compared gelatin contained in freshwater fish including catfish (pangas catfish), red-tailed Asian catfish (Asian redtail catfish), tilapia (nile tilapia), snakehead murrel (striped snakehead) with the commercial gelatin. Gelatin from the catfish has a protein content of $87.10 \pm 0.99$, while commercial gelatin only $78.79 \pm 0.85$. Thus, the protein content in catfish gelatin is greater than that in commercial gelatin. ${ }^{12}$

The protein content of pangas catfish is rich in amino acid. Moreover, its amino acid composition is higher than that of commercial gelatin. ${ }^{12}$ One of the amino acids found in pangas catfish gelatin extract is glutamine. Glutamine plays a role in accelerating fibroblast formation, consequently, accelerating collagen synthesis and also serving as the source of energy in wound healing processes. ${ }^{13,14}$ Accordingly, further study is required to determine the effect of the use of pangas catfish gelatin on collagen synthesis during wound healing processes following tooth extraction in albino rats (Rattus norvegicus).

\section{MATERIALS AND METHODS}

This study was an in vivo laboratory experiment. It was performed in the Biochemical Laboratory, Faculty of Medicine, University of Brawijaya after obtaining an ethical approval No.399/EC/KEPKFKG/12/2017 from the ethical committee of Faculty of Medicine, University of Brawijaya. Animal models involved in this study were male Wistar strain albino rats (Rattus norvegicus). A total of 28 rats, 2-3 months of age, were divided into four groups. The rats in Group-1 (C1) was without pangas catfish gelatin treatment and terminated on day-3. Group-2 (C2) consisted of the animal models without treatment of pangas catfish gelatin that were terminated on day7. The rats in Group-3 (T1) and Group-4 (T2) were treated with pangas catfish gelatin at concentration of $100 \%$ once after extraction and terminated on day 3 and 7 , respectively.

Pangas catfish gelatin was made using the method of making commercial gelatin without a drying process, i.e. the skin of the catfish was peeled and separated from the meat and fat attached to the skin. The catfish skin was stored at $-20^{\circ} \mathrm{C}$. The frozen catfish skin was then thawed at a room temperature and cut to a size of about 1 $\mathrm{cm}^{2}$. The catfish skin was rinsed with lemon water to remove any materials other than fish skin. A hundred gram of the catfish skin were rinsed and immersed in citric acid solution for 12 hours to dilute collagen fibers into fibers/ fibrils, making them easily extracted. The fibers were then neutralized by washing several times until the washing water reached neutral $\mathrm{pH}(6-7)$. The gelatin from pangas catfish skin was extracted using a water bath shaker with distilled water at $60^{\circ} \mathrm{C}$ for 6 hours. The gelatin solution was separated from the remaining skin using Whatman (GE, USA) filter cloth No. 1. The gelatin solution was then cooled at a room temperature until a gelatin gel was formed.

The rats were selected using randomized posttest-only control group design to be divided into four groups, each of which consisted of seven rats. The rats were raised and adapted in the animal care unit of the laboratory for 7 days at room temperature $\left(22^{\circ} \mathrm{C}-24^{\circ} \mathrm{C}\right)$. Prior to the extraction of the left mandibular incisor, the rats were injected with 0.3 $\mathrm{ml}$ ketamine intraperitoneally by the laboratory assistant using the same technique.

The pangas catfish gelatin gel was administered using pipette in $0.1 \mathrm{ml}$ volume into the 
socket once after extraction. The application was performed after the bleeding had stopped then the wound was left open. The control group received no treatment. All the animal models were administered with metamizole at a dose of $500 \mathrm{mg} / \mathrm{mL}$ as an analgesic to reduce post-tooth extraction pain.

Tissue samples were taken on the $3^{\text {rd }}$ and $7^{\text {th }}$ day. The rats were injected with ketamine at a lethal dose, i.e. $9 \mathrm{~mL}, 3$ times. The mandibular bone was harvested with a No.11 scalpel blade. Subsequently, the mandibular bone was put in a tube containing fixative $10 \%$ formalin. The tube was labeled.

The identification of collagen density on the histopathological preparation that was stained using hematoxylin eosin was performed using a digital microscope at $400 x$ magnification on 5 field of view regions. The collagen density was determined using a semi-quantitative scoring system according to $\mathrm{Gal}$ et al. The score 0 indicated the granulation tissue was absent, 1 shows a minimal granulation tissue, 2 reveals a mild granulation tissue, 3 presents a moderate granulation tissue, and 4 for a marked granulation tissue was observed..$^{15}$ The KruskalWallis test followed by Mann-Whitney test was applied to analyze the result. For correlation test, Spearman Rank Correlation was used. The data were analyzed using SPSS Statistics 17.0 program.

\section{RESULTS}

The mandibular bones of the Wistar rats were collected and processed for histology preparation. The classification of collagen fiber distribution in a dental socket of rats is presented in Table 1. The mean of collagen scoring values in the control group on day-3 (C1) was lower than that of day-7 (C2). The scores were 1.13 and 1.76 , respectively. The group treated with pangas catfish gelatin showed lower mean of collagen scoring values on day-3 or T1 group (1.66) than on day-7 or on T2 group (2.93). On day-3, the mean of collagen score in the control group (1.13) was lower than that in the treatment group treated with pangas catfish gelatin (1.66). Moreover, on day-7, the mean of collagen scoring values in the control group (1.76) was lower than that in the treatment group (2.93).
The result of Kruskal-Wallis test showed $p$-value of $p=0.000$, accordingly, the null hypothesis was rejected and it can be concluded that there was a significant difference of collagen synthesis during wound healing process post tooth extraction in the Wistar rats. The result of Mann-Whitney test (Table 2) showed that $C 1$ group demonstrated significantly different collagen score as compared to T1 group, shown by $p=0.019(p<0.05)$. The collagen score of $\mathrm{C} 1$ group were significantly different compared to that of $\mathrm{C} 2$ group which received no treatment of pangas catfish gelatin after 7 days. It was shown by $p=0.019(p<0.05)$. The group of $C 1$ demonstrated significantly different collagen score as compared to T2 group which was treated with pangas catfish gelatin after 7 days, as shown by $p=0.001(p<0.05)$.

Control group-2 (C2) with no treatment of pangas catfish (Pangasius djambal) gelatin post tooth extraction showed significantly different collagen scoring values as compared to treatment group-2 (T2) which was treated with pangas catfish gelatin, as shown by $p=0.002 \quad(p<0.05)$ to compare how wound healing increased in group 2 with and without treatment. Control group-2 (C2) demonstrated no significant difference in the collagen scoring values as compared to treatment group-1 (T1) which was treated with pangas catfish gelatin, as shown by $p=1.000(p>0.05)$. Treatment group-1 (T1) which was treated with pangas catfish gelatin showed significantly different collagen scoring values as compared to treatment group-2 (T2) which also received the same gelatin treatment, as shown by $p=0.002(p<0.05)$.

The Spearman rank correlation test showed data from control group with no treatment of pangas catfish, the strength association $(r)=0.707$ and the direction of association between them were positive, which means that in normal condition, a longer of days, there is increase in collagen synthesis post tooth extraction in Wistar rats. Based on treatment group data, the strength association $(r)=0.949$ and the direction of association between them were positive, which means that in treatment condition, the more significant the increase in collagen synthesis post tooth extraction in albino rats. 


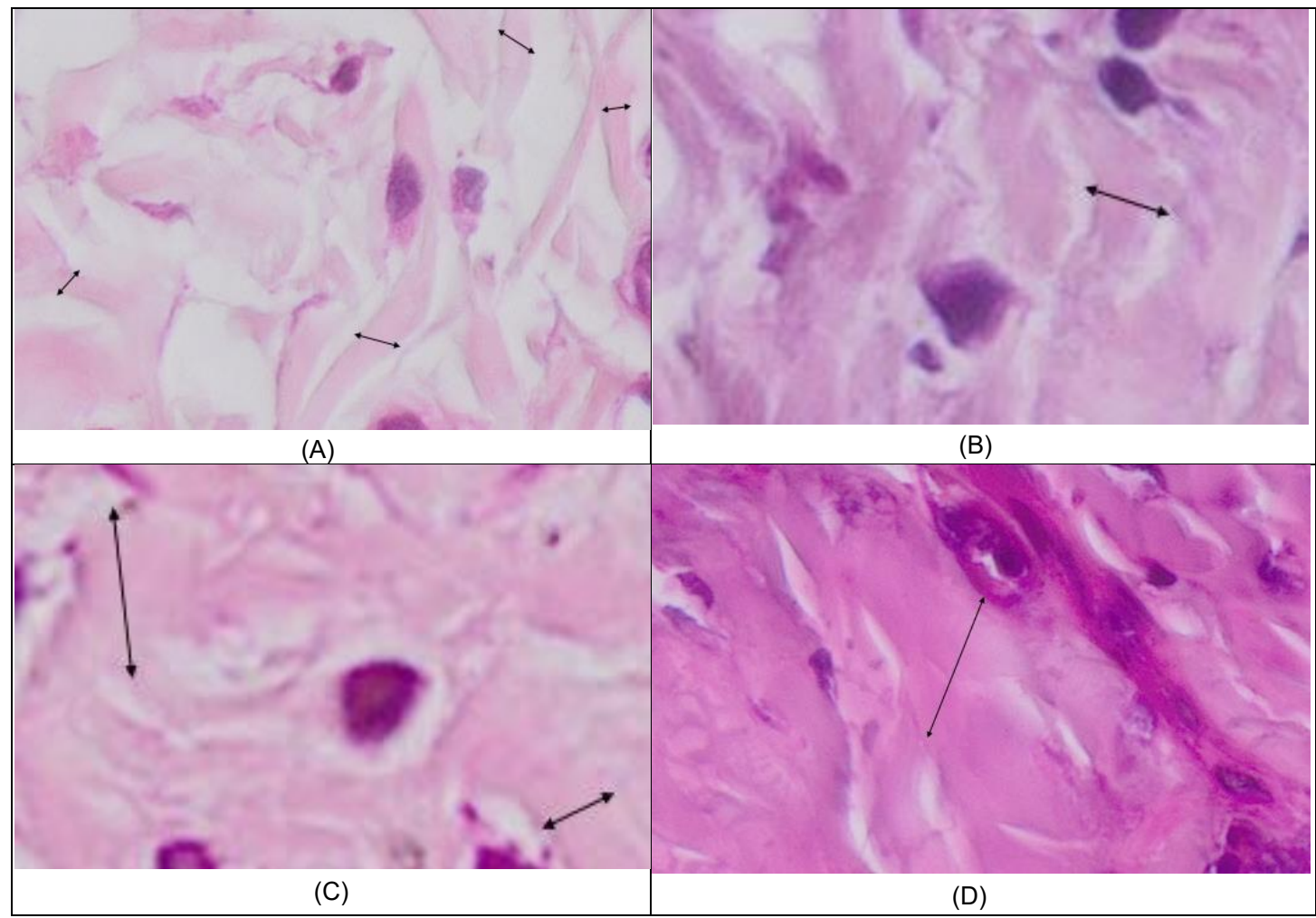

Figure 1. Histological image of collagen under light microscope in one field of view at 400x magnification (arrowhead shows thickness distance of collagen)

Notes: (A) control group on day-3 (C1); (B) treatment group on day-3 (T1); (C) control group on day-7 (C2);

(D) treatment group on day-7 (T2)

Table 1. Collagen scoring value post tooth extraction of albino rats (Rattus norvegicus)

\begin{tabular}{cccc}
\hline Groups & Days & $\begin{array}{c}\text { Mean of collagen } \\
\text { scoring values }\end{array}$ & $\begin{array}{c}\text { Standard } \\
\text { deviation }\end{array}$ \\
\hline C1 & 3 & 1.13 & 0.35 \\
C2 & 7 & 1.76 & 0.68 \\
T1 & 3 & 1.66 & 0.5 \\
T2 & 7 & 2.93 & 0.25 \\
\hline
\end{tabular}

Table 2. The results of comparison test for collagen scoring values using Mann Whitney test

\begin{tabular}{ccl}
\hline Groups & Groups for comparison & \multicolumn{1}{c}{$\mathrm{p}$} \\
\hline & $\mathrm{C} 2$ & $0.019^{*}$ \\
$\mathrm{C} 1$ & $\mathrm{~T} 1$ & $0.019^{*}$ \\
& $\mathrm{~T} 2$ & $0.001^{*}$ \\
$\mathrm{C} 2$ & $\mathrm{~T} 1$ & 1.000 \\
$\mathrm{~T} 1$ & $\mathrm{~T} 2$ & $0.002^{*}$ \\
\hline
\end{tabular}

Notes: *significant

\section{DISCUSSION}

The study results showed that there was an increase in the mean of collagen scoring values from the control groups on day-3 and day-7. The increase was significant, however, the value was not too high because the rats in the control groups received no substance to support the healing process. Therefore, the inflammation phase was normal and the recovery process depended on self healing, thus resulting in low collagen stimulation. ${ }^{1,15}$

The treatment groups showed the mean of collagen scoring values of 1.66 (day-3) and 2.93 (day-7). These results indicated that there was a significant difference of the values among them. In addition, the high mean of collagen scoring values resulted from gelatin treatment, for gelatin is rich in amino acids such as glutamine. Glutamine plays role in tissue repair as it contributes to the increase of fibroblast proliferation, accordingly, it can stimulate collagen to accelerate maturation phase and wound healing process. Gelatin also possesses antimicrobial characteristic, hence it may increase zone of bacterial inhibition on wound. ${ }^{16,17}$ Amino acids especially glutamin content in pangas catfish is higher than that in commercial 
gelatin. In the present study, the collagen scoring values of the treatment groups were higher than those of the control groups. It could be due to the glutamine content in pangas catfish gelatin.

Pangas catfish gelatin contains amino acids which may affect the rate and quality of wound healing. It is also required as a part of the inflammatory process, in the immune response by increasing the function of $T$ lymphocytes so as to increase macrophage activation and in the development of granulation tissue. The main protein synthesized during the healing process is collagen, and the strength of the collagen determines wound strength. ${ }^{18,19}$

Based on literature, inflammatory process will significantly decrease on day 5 and change to proliferative phase where many kinds of growth factors such as epithelial growth factors and fibroblast growth factors participate in this phase. The process starts with the formation of fibroblast cells. Fibroblasts will synthesize ground substance, i.e mucopolysaccharide which may connect collagen fibers. Collagen may provide strength to healing tissues, encouraging quick wound closure. ${ }^{20,21,22}$ According to Spearman rank correlation test value of the control and treatment groups, the use of pangas catfish gelatin could result in higher increase in collagen synthesis than those with no treatment of pangas catfish gelatin.

\section{CONCLUSION}

In conclusion, pangas catfish gelatin has an effect on increasing collagen synthesis during dental socket healing process post tooth extraction in albino rats (Rattus norvegicus).

\section{REFERENCES}

1. Wang $\mathrm{PH}$, Huang BS, Horng $\mathrm{HC}$, Yeh $\mathrm{CC}$, Chen YJ. Wound healing. J Chinese Med Assoc. 2018; 81(2): 94-101. doi: 10.1016/j.jcma.2017.11.002

2. Böhm S, Strauß C, Stoiber S, Kasper C, Charwat $\mathrm{V}$. Impact of source and manufacturing of collagen matrices on fibroblast cell growth and platelet aggregation. Materials (Basel). 2017; 10(9): 1-14. doi: 10.3390/ma10091086
3. Vieira $A E$, Repeke $C E$, De Barros Ferreira $S$, Colavite PM, Biguetti CC, Oliveira RC, Assis GF, Taga R, Trombone AP, Garlet GP. Intramembranous bone healing process subsequent to tooth extraction in mice: Microcomputed tomography, histomorphometric and molecular characterization. PLoS One. 2015; 10(5): 1-22.

doi: 10.1371/journal.pone.0128021

4. Zhou S, Salisbury J, Preedy VR, Emery PW. Increased collagen synthesis rate during wound healing in muscle. PLoS One. 2013; 8(3): 8-11. doi: 10.1371/journal.pone.0058324

5. Nissinen LM, Kähäri VM. Collagen turnover in wound repair - a macrophage connection. J Invest Dermatol. 2015; 135(10): 2350-2352. doi: 10.1038/jid.2015.246

6. Sultana J, Molla MR, Kamal M, Shahidullah M, Begum F, Bashar MA. Histological differences in wound healing in Maxillofacial region in patients with or without risk factors. Bangladesh J Pathol. 2009; 24(1): 3-8. doi: 10.3329/bjpath.v24i1.2874

7. Sun BJ, Chen HJ, Chen Y, An XD, Zhou B Sen. The risk factors of acquiring severe hand, foot, and mouth disease: A meta-analysis. Can J Infect Dis Med Microbiol. 2018; 2018(24): 1-12. doi: $10.1155 / 2018 / 2751457$

8. Arzt J, Belsham GJ, Lohse L, Bøtner A, Stenfeldt C. Transmission of foot-andmouth disease from persistently Infected Carrier Cattle to Naive Cattle via Transfer of Oropharyngeal Fluid. mSphere. 2018; 3(5): 1-12. doi: $10.1128 / \mathrm{msphere} .00365-18$

9. Nuge T, Hoque ME, Yeow TK, Nordin N, Chowdhury M. Electrospun gelatin composite nanofibres: A review on structural and mechanical characterizations. Regen Res. 2013; 2(2): 39-42.

10. Abdullah MSP, Noordin MI, Mohd Ismail SI, Mustapha NM, Jasamai M, Danik MF, Ahmad WAW, Shamsuddin AF. Recent advances in the use of animal-sourced gelatine as natural polymers for food, cosmetics and pharmaceutical applications. Sains Malaysiana. 2018; 47(2): 323-336. doi: 10.17576/jsm-2018-4702-15 
11. Hoque $M$, Nuge $T$, Yeow $T$, Nordin $N$, Prasad R. Gelatin based scaffolds for tissue engineering-a review. Polym Res J. 2015; 9(1): 15.

12. Ratnasari I, Yuwono SS, Nusyam H, Widjanarko SB. Extraction and characterization of gelatin from different fresh water fishes as alternative sources of gelatin. Int Food Res J. 2013; 20(6): 3085-3091.

13. Li J, Wang Q, Gu Y, Zhu Y, Chen L, Chen Y. Production of composite scaffold containing silk fibroin, chitosan, and gelatin for $3 d$ cell culture and bone tissue regeneration. Med Sci Monit. 2017; 23: 5311-5320. doi: 10.12659/MSM.905085

14. Sunil S, Harsha M. A Modified method for bone regeneration using gelatin sponge with bone graft in treating an osseous defect after root resection. J Heal Sci Res. 2017; 8(2): 80-83. doi: 10.5005/jp-journals-10042-1055

15. Gal P, Kilik R, Mokry M, Vidinsky B, Vasilenko T, Mozes S, Bobrov N, Tomori Z, Bober J, Lenhardt L. Simple method of open skin wound healing model in corticosteroid-treated and diabetic rats: Standardization of semiquantitative and quantitative histological assessments. Vet Med (Praha). 2008; 53(12): 652-659. doi: 10.17221/1973-VETMED

16. Anderson K, Hamm RL. Factors that impair wound healing. J Am Coll Clin Wound Spec. 2012; 4(4): 84-91.

doi: 10.1016/j.jccw.2014.03.001
17. Sipahi S, Gungor O, Gunduz M, Cilci M, Demirci MC, Tamer A. The effect of oral supplementation with a combination of betahydroxy-beta-methylbutyrate, arginine and glutamine on wound healing: A retrospective analysis of diabetic haemodialysis patients. BMC Nephrol. 2013; 14(1): 2-7.

18. Chen J, Gao K, Liu S, Wang S, Elango J, Bao B, Dong J, Liu N, Wu W. Fish collagen surgical compress repairing characteristics on wound healing process in vivo. Mar Drugs. 2019; 17(1): 1-12. doi: 10.3390/md17010033

19. Felician FF, Yu RH, Li MZ, Li CJ, Chen $H Q$, Jiang Y, Tang T, Qi WY, Xu HM. The wound healing potential of collagen peptides derived from the jellyfish Rhopilema esculentum. Chinese J Traumatol - English Ed. 2019; 22(1): 12-20. doi: 10.1016/j.cjtee.2018.10.004

20. Davison-Kotler E, Marshall WS, García-Gareta $E$. Sources of collagen for biomaterials in skin wound healing. Bioengineering. 2019; 6(3): 56. doi: 10.3390/bioengineering6030056

21. Mardiyantoro F, Munika K, Sutanti V, Cahyati M, Pratiwi AR. Penyembuhan luka rongga mulut. Malang: UB Press; 2018. 1-13.

22. Böhm S, Strauß C, Stoiber S, Kasper C, Charwat V. Impact of source and manufacturing of collagen matrices on fibroblast cell growth and platelet aggregation. Materials (Basel). 2017;10(9). doi: 10.3390/ma10091086 